\title{
Contiguous notches interaction on Ck45 shaft under reversed bending loading: experimental, metallographical and analytical approach
}

\author{
Antonios D. Tsolakis ${ }^{*}$, Konstantinos I. Giannakopoulos, Efstathios D. Makarigakis \\ Piraeus University of Applied Sciences, Department of Mechanical Engineering, Egaleo, Greece
}

\begin{abstract}
In mechanical engineering design it is common for multiple stress concentration areas to coexist adjacently, where the existing analytical theory cannot be used to assess the effect. The effect of adjacent step and keyway on a DIN CK 45 shaft has been investigated in the present paper. For this purpose, a DIN CK45 steel shaft specimen with a standardized keyway and a diameter-step has been tested under rotating bending in order to investigate the interaction of two distinct stress concentration areas. All fragment specimens have metallographically examined. Analytical and numerical methods have been used to support the conclusions.
\end{abstract}

\section{Introduction}

External geometrical notches, as fillets, grooves, holes etc., are a common design technique for mounting power-transmitting elements on shafts. As these elements exert forces, in perpendicular to the shaft axis direction, produce bending stresses to shaft, in the region of hub attachment with the abrupt changes of geometry. For stand -alone notches on shafts the fundamental theory for stress concentration comes from R.E. Peterson [1]. After this many investigators have worked on diameter step [2-4] and keyseat [5-10] impact on shafts fatigue behavior. On the other hand, in shaft design, it is very common the coexistence of two geometrical notches in the same region. Especially, an adjacent diameter step with a key is an accustomed design for both perpendicular and axial mounding and retaining of machine elements on shafts. For this case there are very few literature references [11] covering a limited range of cases.

\section{Specimens' material and geometry}

The steel used for manufacturing the specimens according to the DIN standard for steels is CK45 grade and its chemical composition is shown on table 1. The specimens were manufactured following the guidelines of ISO 1143:2010 [12]. After the machining process, the specimens were gradually polished in order to reduce surface roughness and then stress relieved in salt bath in order to eliminate remaining stresses.

* Corresponding author: adtsolakis@puas.gr 
Table 1. CK45 Chemical Composition.

\begin{tabular}{|c|c|}
\hline $\begin{array}{c}\text { Chemical } \\
\text { Element }\end{array}$ & Percentage \\
\hline Carbon & 0.45 \\
\hline Silicon & 0.25 \\
\hline Manganese & 0.65 \\
\hline Sulfur & $>0.030$ \\
\hline
\end{tabular}

Four types of specimens were manufactured. One single notched (only stepped with $0.4 \mathrm{~mm}$ radius fillet) and three with a keyseat with different relative distances from the shaft step (see figure 1). All specimens' geometry fitted at the testing apparatus TERCO MT 3012-E. The keyseats are profiled type and was manufactured according to ISO/R 773:1969 [13], on the shaft diameter of $10 \mathrm{~mm}$.

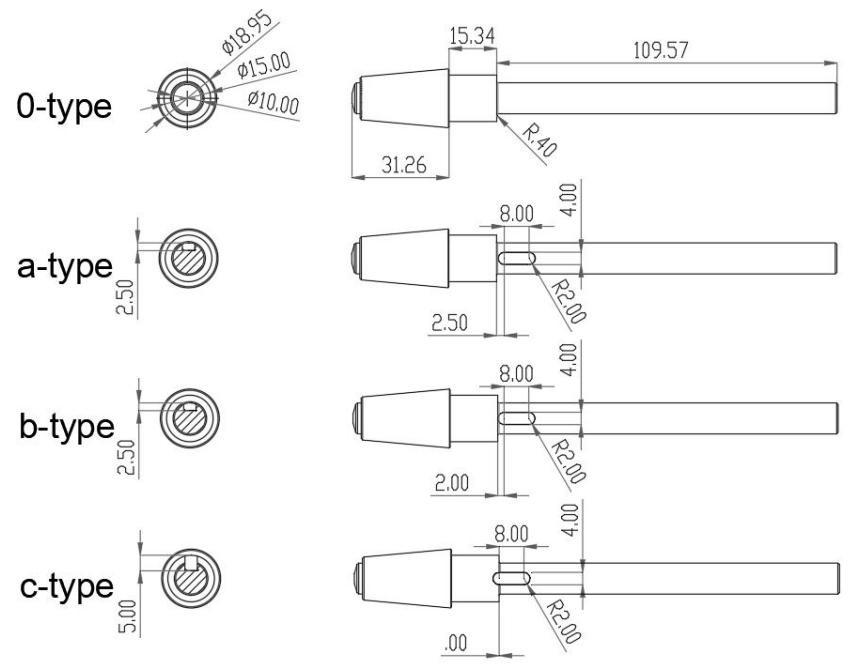

Fig. 1. Specimens types geometries

\section{Experimental approach}

For the fatigue behavior of the specimens a number of bending fatigue tests was executed. The test procedure the ISO 1143:2010 standard was taken into consideration.

\subsection{Apparatus and set-up}

For the experimental method a testing apparatus originally designed for material fatigue testing was used. The machine we used for the tests is a TERCO brand, MT 3012-E model. The testing apparatus uses an asynchronous single phase electric motor in order to rotate the specimen and a force application system capable of applying a maximum value of $300 \mathrm{~N}$. A schematic of the working principle of the machine used in the test is shown in figure 2 . 


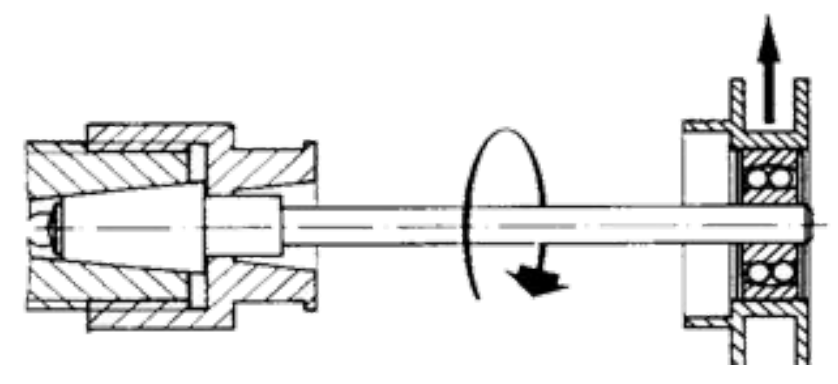

Fig. 2. TERCO MT3012-E operating principal

Twelve specimens of each geometrical type were prepared according to the ISO 1143:2010 [12] guidelines and tested for three different bending loads $100 \mathrm{~N}, 200 \mathrm{~N}$ and $300 \mathrm{~N}$ as a first step and consequently other values of loads applied, depended on the specimens behaviour, in order to approach the fatigue endurance limit. In all tests the rotational speed of the specimens was $3000 \mathrm{rpm}$.

\subsection{Experimental results}

The experimental results are summarized in the diagram shown in figure $3 \mathrm{a}$, where the number of specimens' life-cycles plotted versus applied bending loads as they described in paragraph 3.1 above. At all the single notched specimens fractured started from the notch, as it was expected but at all the double notched specimens the fracture started from keyseat upper edge as shown in figure $3 b$ where typical fractured surfaces from b- type and $c$-type specimens are captured via stereoscope.
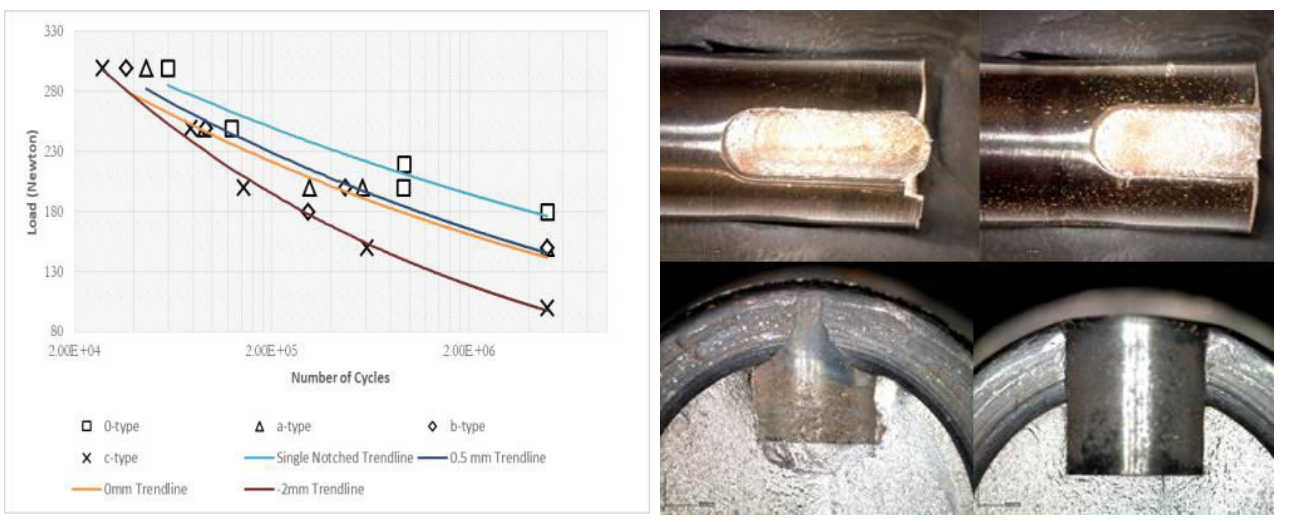

Fig. 3. a) number of specimen life-cycles versus applied load, b) typical fractured surfaces

\section{Metallographic analysis}

With the aid of an scanning electron microscope, the fracture surfaces of the specimens were examined (figure $4 \mathrm{a}, \mathrm{b}$ ). As it can be seen in both figures the main fracture mechanism is ductile and the fatigue crack initiation is marked. The region that the fracture seems to have been ignited is exactly on the end-point of keyway upper edge straight part. 


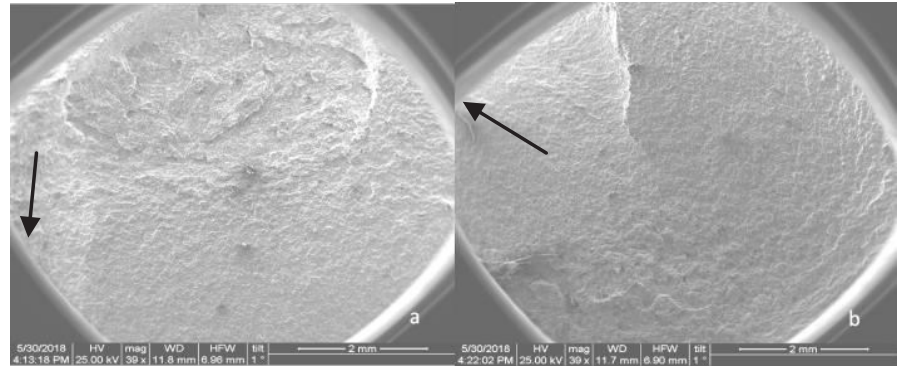

Fig.4. Fracture surfaces of specimens under $200 \mathrm{~N}$ applied load, (a) c-type specimen,(b) b-type specimen.

In figure $5(\mathrm{a}-\mathrm{c})$ the fracture surfaces of three specimens under the applied load of $200 \mathrm{~N}$ are shown. As it can be said, all specimens have shown a ductile fracture with visible dimples. In all figures there are signs of river patterns and various microcracks. Their direction seems to be variable as their length. It was observed that fatigue cracks that started at nearby positions could either merge or inhibit each other's growth.

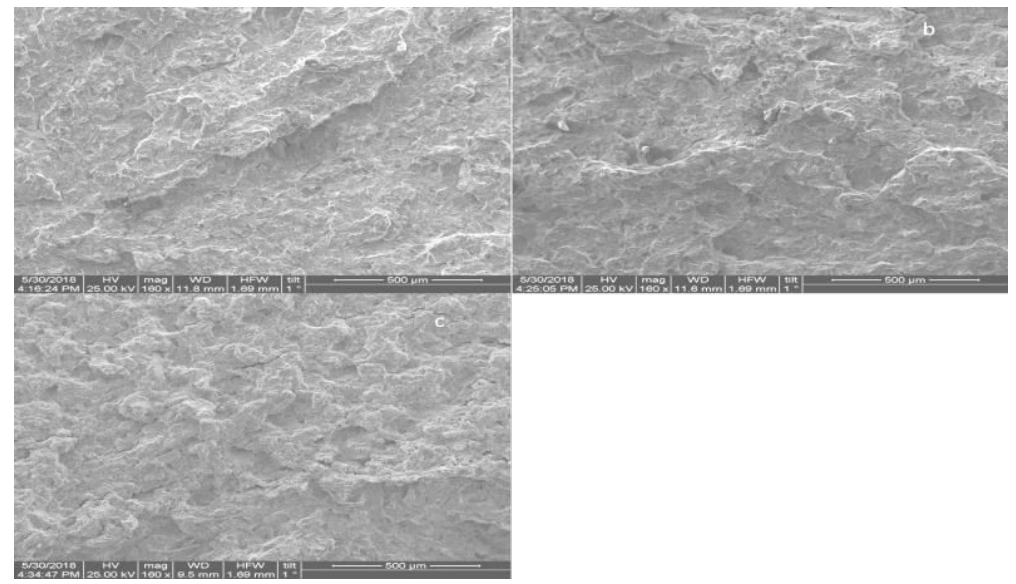

Fig.5. Fracture surfaces of specimens under $200 \mathrm{~N}$ applied load, (a) c-type specimen, (b) b-type specimen, (c) a-type specimen.

\section{Analytical approach}

The existing stress concentration estimation theory on shafts covers only the stand-alone notches stress concentration factors and it is useless for contiguous notches calculation. For the static stress estimation of the double -notched regions Finite Elements Analysis was used in an attempt to approach the static stress coefficient factor $K t$ with respect to the solid section normal stress with diameter equal to $10 \mathrm{~mm}$.

\subsection{Single notch stress concentration factors}

According to R.E. Peterson [1] the stress concentration factor of a shaft step can be calculated using the formula 1 . 


$$
K t=C_{1}+C_{2}\left(\frac{2 h}{D}\right)+C_{3}\left(\frac{2 h}{D}\right)^{2}+C_{4}\left(\frac{2 h}{D}\right)^{3}
$$

Where $D$ is the larger shaft's diameter and $h$ the step height.

Applying formula (1) for the tested single stepped specimen geometry, for

$$
\frac{h}{r}=\frac{2.5}{0.4}=6.25 \rightarrow 2 \geq \frac{h}{r} \geq 20
$$

The $C$ parameters are

$$
\begin{aligned}
& C_{1}=1.232+0.832 * \sqrt{\frac{h}{r}}-0.008 * \frac{h}{r}=3.262 \\
& C_{2}=-3.813+0.968 * \sqrt{\frac{h}{r}}-0.260 * \frac{h}{r}=-3.018 \\
& C_{3}=7.423-4.868 * \sqrt{\frac{h}{r}}+0.869 * \frac{h}{r}=0.684 \\
& C_{4}=-3.839+3.070 * \sqrt{\frac{h}{r}}-0.600 * \frac{h}{r}=0.086
\end{aligned}
$$

Thus the value of $K_{t}$ resulting equal to 2.34

For keyways, on the other hand, the fatigue concentration factor $K t$ for profiled keyseats according to N.L.Petersen [5] derives from formula 5 below

$$
K_{t}=\left(1.4786 \frac{t}{b}+0.6326\right) *\left(\frac{r}{d}\right)^{\left[0.869(t / d)^{2}-0.4392(t / d)-0.2369\right]}
$$

Where $b$ is the keyseat width, $t$ the depth, $\mathrm{r}$ the fillet ratio at the bottom edge and $\mathrm{d}$ the shaft diameter. is the larger shaft's diameter and $h$ the step height.

Applying formula 4 for the specimens keyseat the value of $K_{t}$ resulting equal to 3.85

The dynamic loading stress concentration factor $K f$ derives from the equation 5

$$
K_{f}=1+q\left(K_{t}-1\right)
$$

Where the notch sensitivity factor q for CK45 for the stepped geometry its value is 0.68 and for the keyseat equal to 0.4 , according to [9], which gives $K f$ equal to 1.91 and 2.14 respectively.

\subsection{Finite elements analysis}

For finite elements analysis the $3 \mathrm{~d}$ models of the specimens was created with Autodesk Inventor solid modeller and for the simulation the Nastran solver was launched. Every specimen type was analysed for the three bending loads as applied in the bending test $(100 \mathrm{~N}, 200 \mathrm{~N} \& 300 \mathrm{~N})$. The simulation ran for discrete force angles of a half circle rotation in order to have a dynamic loading view (see figure 2a), thus 22 loading conditions were 
analysed for each specimen type and each loading. In total 198 simulations ran. The PSS linear solver chosen and the largest solution error measure was 1,217E-10 (with values less than 1.0E-07 are generally considered acceptable). The largest solid element relative stress error was $2,65 \mathrm{E}-2$ which represents a measure of mesh convergence, while values greater than 0.01 may indicate that further mesh refinement. The mesh parameters are summarized in the table 2 and in figure $6 \mathrm{~b}$ the controlled meshed areas are indicated.

Table 2. Finite elements analysis mesh parameters

\begin{tabular}{|c|c|c|c|c|c|}
\hline $\begin{array}{c}\text { Body } \\
\text { element size } \\
(\mathrm{mm})\end{array}$ & $\begin{array}{c}\text { Controlled } \\
\text { areas } \\
\text { element size } \\
(\mathrm{mm})\end{array}$ & $\begin{array}{c}\text { Element type } \\
\text { and order }\end{array}$ & $\begin{array}{c}\text { Refinement } \\
\text { ratio }\end{array}$ & $\begin{array}{c}\text { Max element } \\
\text { growth rate }\end{array}$ & $\begin{array}{c}\text { Triangle } \\
\text { angle (max- } \\
\text { min) }\end{array}$ \\
\hline 2.8 & 0.1 & $\begin{array}{c}\text { Tetrahedrals } \\
\text { parabolic }\end{array}$ & 0.6 & 1.5 & $30^{\circ}-20^{\circ}$ \\
\hline
\end{tabular}
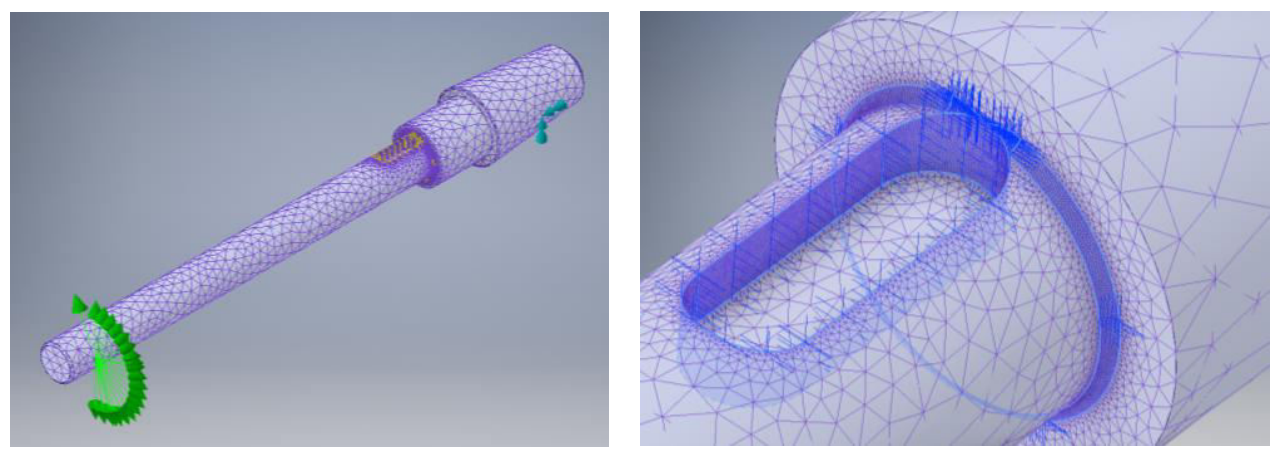

Fig. 6. a) Typical meshed solid and applied loads- b) Controlled mesh areas

\subsection{Finite elements results}

For each simulation the Von Mises, the $1^{\text {st }}$ Principal and the z-normal stresses were monitored at two discrete points: One on the ratio fillet area (B) at the diameter step and one on the upper keyseat edge (A) as shown in figure 7 , the point where the fraction ignited. These two points selected as the points of the maximum stress values which occurred at the angle of $24^{\circ}$ of the bending load respect to the keyseat centreline as shown in figure 7.
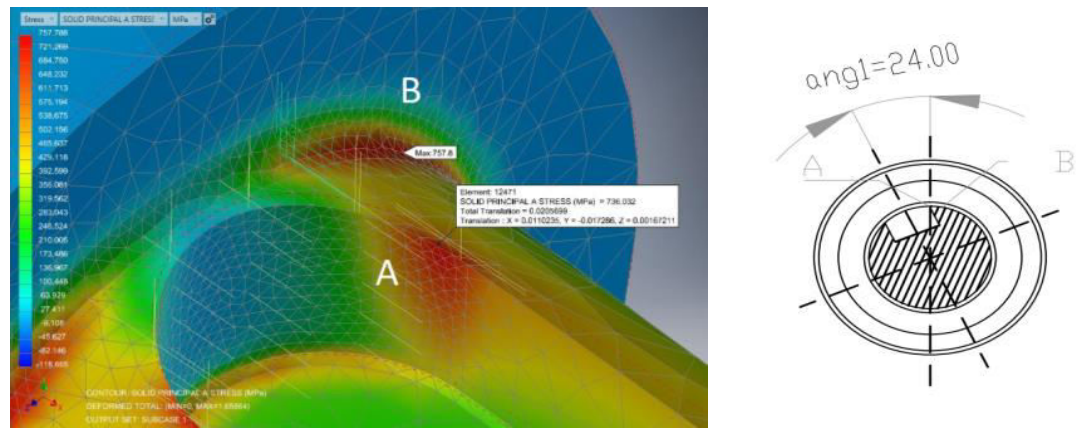

Fig. 7. Stress monitoring points 
In the figure 8 and the table 3 below some indicative results from the FEA analysis are presented for $300 \mathrm{~N}$ bending load. Especially in the table 3 the results are in comparison with the analytical stress result values.
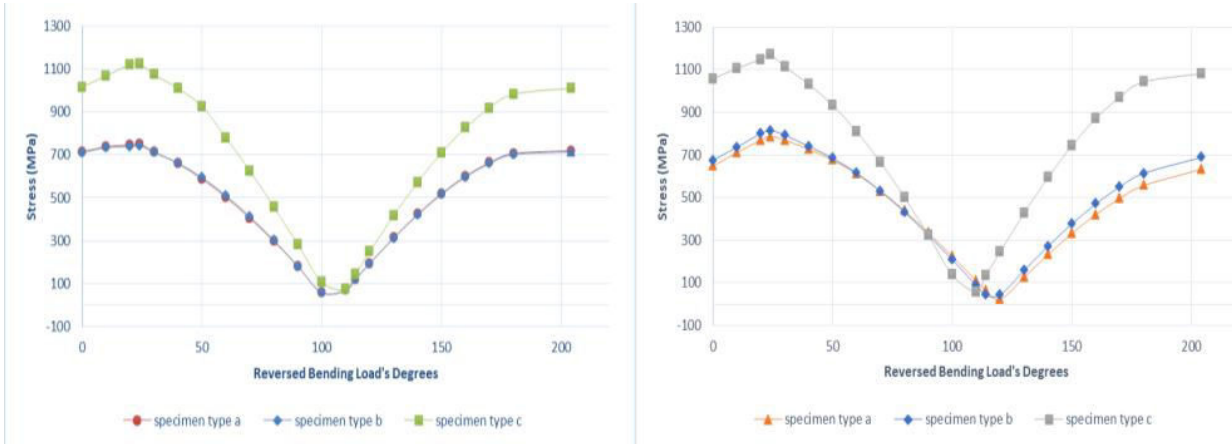

Fig. 8. Typical FEA results showing Von Mises stresses at monitoring points A (left) and B (right)

Table 3. Inticative results for $300 \mathrm{~N}$ bending load

\begin{tabular}{|c|c|c|c|c|c|c|c|}
\hline & $\begin{array}{c}\text { 0-type } \\
\text { B-point }\end{array}$ & $\begin{array}{l}\text { a-type } \\
\text { A-point }\end{array}$ & $\begin{array}{l}\text { a-type } \\
\text { B-point }\end{array}$ & $\begin{array}{l}\text { b-type } \\
\text { A-point }\end{array}$ & $\begin{array}{l}\text { b-type } \\
\text { B-point }\end{array}$ & $\begin{array}{l}\text { c-type } \\
\text { A-point }\end{array}$ & $\begin{array}{c}\text { c-type } \\
\text { B-point }\end{array}$ \\
\hline \begin{tabular}{|c|}
$\begin{array}{c}\text { Analytical } \\
\text { calculation } \\
\text { stress } \\
\text { values }\end{array}$ \\
\end{tabular} & $\begin{array}{l}732.6 \\
\text { Mpa }\end{array}$ & $\begin{array}{c}1179.3 \\
\text { Mpa }\end{array}$ & $\begin{array}{l}732.6 \\
\text { Mpa }\end{array}$ & $\begin{array}{c}1185.1 \\
\mathrm{Mpa}\end{array}$ & $\begin{array}{l}732.6 \\
\text { Mpa }\end{array}$ & $\begin{array}{c}1208.7 \\
\text { Mpa }\end{array}$ & $\begin{array}{c}- \\
\mathrm{Mpa}\end{array}$ \\
\hline $\begin{array}{c}\text { FEA } \\
1^{\text {st }} \text { Principa } \\
\text { stresses } \\
\end{array}$ & $\begin{array}{c}808.2 \\
\text { Mpa }\end{array}$ & $\begin{array}{l}751.8 \\
\text { Mpa }\end{array}$ & $\begin{array}{c}942.4 \\
\text { Mpa }\end{array}$ & $\begin{array}{l}745.2 \\
\text { Mpa }\end{array}$ & $\begin{array}{c}982.5 \\
\text { Mpa }\end{array}$ & $\begin{array}{c}1202.9 \\
\mathrm{Mpa}\end{array}$ & $\begin{array}{c}1257.9 \\
\mathrm{Mpa}\end{array}$ \\
\hline
\end{tabular}

\section{Conclusions}

As it was expected the fatigue behaviour of the double notched shaft in cyclic bending loading depends upon the step-keyseat relative distance. The behaviour of the a and $b$ type are similar with the specimens with the keyseat cut in the shafts step to show the worst fatigue behavior. Beside these the following conclusion is the most critical and unexpected: Fragmentation occurs in an area where numerical methods fall to indicate. There is a remarkable diverge of the numerical and analytical results for the double notched specimens. Since the analytical method points at the keyseat edge (point-A), the static stresses derived from FEA indicate the step fillet (point-B) as the high stressed region. At this point it must be mentioned that for this assumption the notch sensitivity factor has not been taken into account. As the FEA results only static stresses the contribution of the method to fatigue behaviour is indicative but not negligible. The cases of the conjucting notches is a wide field of investigation and the determination of the design parameters for the safety of such geometries in fatigue is a subject of future study and research.

The authors would like to acknowledge Dr. Travlos and Dr. K.Giannakopoulos from the Electron Microscopy Laboratory of the NCSR "Demokritos", for their contribution to the metallographic analysis with the aid of a Scanning Electron Microscope 


\section{References}

1. R. E. Peterson, Stress Concentration Design Factors (John Wiley \& Sons, New York, 1953)

2. A. Göksenli, I.B. Eryürek, EFA, 16, 1011-1346 (2009)

3. Ž. Domazet, F. Lukša, M. Bugarin, EFA, 44, 125-135 (2014)

4. R. A. Gujar, S. V. Bhaskar, IJERA, 3, 1061 - 1066 (2013)

5. $\quad$ N. L. Pedersen, JSAED, 45, 593-604 (2010)

6. P.E. Xiaobin Le, Zelong Le, 120th ASEE Annual Conference and Exposition,6755 (2013)

7. H.R. Prajapati, B.P. Patel, N. V. Patel, UJR,1, 45-57 (2015)

8. H. Fessler, C. Rogers, P. Stanley, JSA, 4, 180-189 (1969)

9. J.E. Shigley, C.R. Mischke, Mechanical Engineering Design, 5th Ed. (McGraw-Hill, Inc., New York, 1989).

10. A.F. Madayag, Metal Fatigue,(New York, 1969)

11. W.D. Pilkey, D.F.Pilkey, Petersons Stress Concentration Factors, 3rd Ed. (John Wiley \& Sons, New York, 2008)

12. ISO 1143:2010, Metallic materials - Rotating bar bending fatigue testing

13. ISO/R 773:1969 Rectangular or square parallel keys and their corresponding keyways 